\title{
Measurements of snow- and glacier-covered areas with single-polarization SAR
}

\author{
JiAnCheng SHi AND JeFF DozieR \\ Center for Remote Sensing and Environmental Optics, and Department of Geography, \\ University of California, Santa Barbara, CA 93106, U.S.A.
}

\begin{abstract}
Climatological and hydrological investigations in mountainous regions frequently require delineation of the areas covered by snow and glacial ice. Active microwave sensors can discriminate snow and glacier from other targets, are effective under all weather conditions, and have a spatial resolution compatible with the topographic variation in alpine regions. Using data acquired with the NASA AIRSAR, which operates at three frequencies and four combinations of polarization, we examine the usage of synthetic aperture radar (SAR) to map snow- and glaciercovered areas. In order to assess the available SARs that operate from satellites, we analyze single-frequency, single-polarization data, and we compare our results with images from the Landsat Thematic Mapper obtained under clear conditions only a few days after the SAR flight. Single polarization, C-band $(5.3 \mathrm{GHz})$ SAR data can discriminate between areas covered by wet snow from those that are ice-free, but do not easily separate glacier ice from snow and rock. L-band SAR $(1.25 \mathrm{GHz})$ data cannot discriminate between snow and glacier ice. The accuracy $(74 \%)$ of SAR is high enough to justify its use as the data source in areas that are too cloud-covered to obtain reliable data from the thematic mapper.
\end{abstract}

\section{INTRODUCTION}

Climatological and hydrological investigations in mountainous regions frequently require delineation of the areas covered by snow and glacial ice. For example, the snow line on glaciers is used in hydrological applications and mass-balance studies. Visible and near-infrared sensors have been used extensively to delineate areas of snow and ice cover, but they cannot see through clouds, which are pervasive in some regions in some seasons. Timely measurements of snow cover are needed for operational hydrology, and opportunities for obtaining suitable data from visible sensors can be infrequent. Microwave remote-sensing instruments, particularly active sensors, can see through clouds.

Active microwave sensors can discriminate between snow and bare ground, and have a spatial resolution compatible with the topographic variation in alpine regions. Starting with the launches of the European Remote Sensing Satellite (ERS-1) in 1991 and the Japanese Earth Resources Satellite (JERS-1) in 1992, there will be many SAR sensors in space during this decade, including Shuttle Imaging Radar (SIR-C, 1993, 1994 and 1995), Radarsat (1994) and ERS-2 (1994). In order to use effectively these data operationally, it is necessary to evaluate their capability to map snow and glacier surfaces.

In attempting to use SAR data to map snow and glaciers over remote and inaccessible areas, we are faced with two major problems: compensation must be made for the effects of rugged terrain; and snow and glaciers must be distinguished from other surface covers.

The capability of polarimetric SAR for snow and glacier mapping in alpine regions has been established (Shi and others, 1990). In this study, the capabilities of single-polarization SAR for snow and glacier mapping will be addressed. We derive a technique to minimize the effect of the local incidence angle on mapping snow- and glacier-covered areas in alpine regions, and we evaluate the capabilities of single-polarization SARs, comparing the results with those obtained from co-registered Landsat Thematic Mapper imagery.

\section{EXPERIMENT DESCRIPTIONS}

We analyze data at two frequencies, $1.25 \mathrm{GHz}$ ( $\mathrm{L}$ band) with $\mathrm{HH}$ polarization and $5.3 \mathrm{GHz}$ (C band) with $\mathrm{VV}$ and $\mathrm{HH}$ polarizations, from an SAR overflight by the NASA/JPL DC-8 on 18 August 1989 over Hintereisferner and Kesselwandferner in the Ötztal Alps, Austria. The flight altitude of $8200 \mathrm{~m}$ was about $5500 \mathrm{~m}$ above the mean terrain altitude of the study site; the processed SAR scene covered about $12 \mathrm{~km} \times 10 \mathrm{~km}$. The radar-look angle ranged from about $10^{\circ}$ to $63^{\circ}$. The data were processed at JPL and made available in a four-look compressed-data format with $12.1 \mathrm{~m}$ azimuth resolution and $6.7 \mathrm{~m}$ slant-range resolution. Using a digital-elevation model (DEM) of the study site, with the generated incidence- and antenna-angle maps, AIRSAR data can 


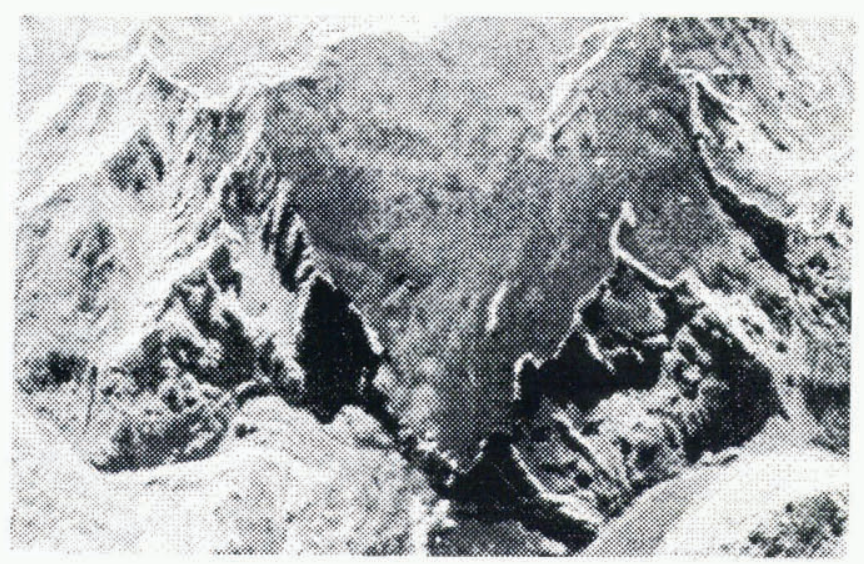

Fig. 1. C-band $(5.3 \mathrm{GHz}) \mathrm{VV}$ polarization SAR image of the study site (Hintereisferner and Kesselwandferner) located at about $46^{\circ} 28.8^{\prime} \mathrm{N}, 10^{\circ} 27.6^{\prime} \mathrm{E}$. The scene covers about $12 \mathrm{~km} \times 10 \mathrm{~km}$.

be calibrated (van Zyl and Shi, in press) so that simulation of space-borne SAR measurements is possible.

Figure 1 shows a C-band image of the study site with VV polarization in a slant-range presentation. The test site includes narrow valleys, which become wider and are covered by glaciers at elevations above $2500-2800 \mathrm{~m}$. The overall test-site altitude ranges from 1800 to $3700 \mathrm{~m}$. The firn areas of Gepatschferner (glacier area $17.7 \mathrm{~km}^{2}$ ) and Kesselwandferner $\left(4.2 \mathrm{~km}^{2}\right)$ form a large plateau with comparatively gentle topography. Hintereisferner has an area of $9.1 \mathrm{~km}^{2}$. At the time of the radar survey, the snow cover was wet at all elevations. The liquid-water content of the top snow layer was 5-6\% by volume at elevations of $3000 \mathrm{~m}$, and decreased to 2 or $3 \%$ at the highest elevations. Snow densities ranged from 492 to $580 \mathrm{~kg} \mathrm{~m}^{-3}$, depths from 0.45 to $1.14 \mathrm{~m}$. Snow-grain radii decreased with depth from 1.0 to $1.5 \mathrm{~mm}$ in the top snow layer to $0.5-1.0 \mathrm{~mm}$ at the base of the snowpack. There were several pronounced ice layers and ice lenses in the snow pits. Typically, the first ice lenses occurred at depths of about $10 \mathrm{~cm}$. Surface-roughness measurements of the snow cover showed standard deviations of surface height of 1-2 cm; correlation lengths typically ranged from 15 to $20 \mathrm{~cm}$, with minima and maxima of 10 and $25 \mathrm{~cm}$. Before and during the SAR overflight, heavy precipitation fell over the entire test site, up to elevations of about $3300 \mathrm{~m}$ as rain, and above that as wet snow. A cloud-free TM image of the test site was acquired $6 \mathrm{~d}$ after the AIRSAR overflight, providing a valuable opportunity for comparative and combined studies with the radar data.

\section{BACK-SGATTERING RESPONSE TO TARGETS}

A conventional single-polarization SAR imager provides high-resolution digital images but with only one fixed polarization state of the antenna. With only one intensity measurement per pixel, we thus have to rely mainly on the radiometric properties to distinguish snow- and glacier-covered area from other targets, such as bare ground or vegetation. In this study, three classes were chosen in the study area for classification testing:

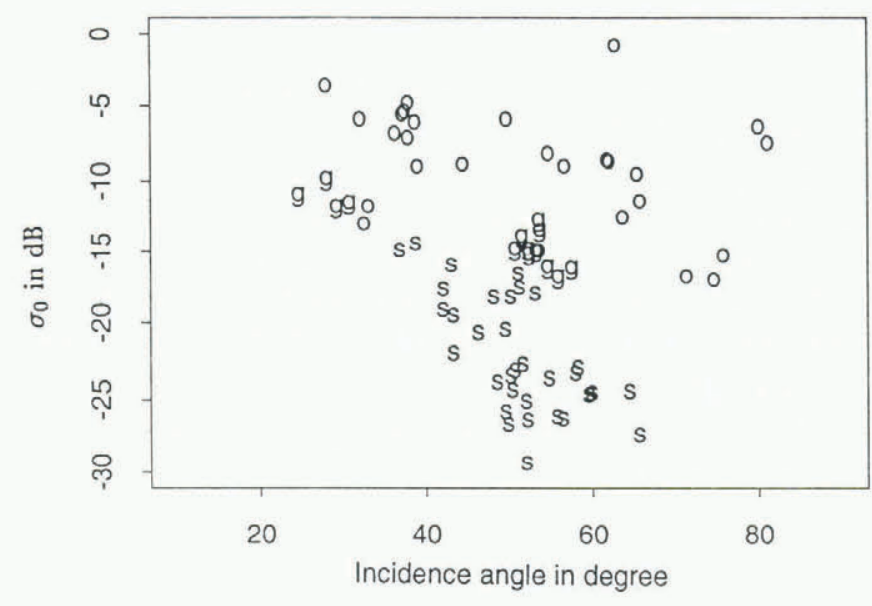

Fig. 2. Measured back-scattering coefficients at $C$ band with VV polarization for three targets. $s$ - snow; $g-$ glacier ice; o-other, mainly rock and moraine.
$\mathrm{S}$ - Wet snow
$\mathrm{G}$ - Glacier ice
$\mathrm{O}$ - Other, mainly rock and moraine.

The representative back-scattering coefficients for each class were the average values in the training sites. Selection of the training sites is based on TM data, mapped as snow-covered, glacier-covered and other regions. Figure 2 shows the mean values in a $10 \times 10$ sampling window of the back-scattering coefficients from these three targets at $5.3 \mathrm{GHz}$ with VV polarization, like the ERS-1 sensor.

Since back-scattering signals from bare rock, soil and glacier are dominated by surface back-scattering, the back-scattering coefficients at a given incidence angle mainly depend on dielectric properties and surface roughness. Back-scattering from wet snow-covered areas is dominated by both surface and volume scattering, depending on their physical parameters and surface roughness (Shi and Dozier, 1992). Generally, the dominant scattering mechanics are surface back-scattering at small incidence angle and volume back-scattering at large incidence angle. Since the surface of rock and soil is rougher than wet snow and glacier, the back-scattering coefficients from rock or soil are greater. The roughness of glacier-ice surfaces is generally smaller than rock or soil but greater than wet snow, hence the magnitude of their back-scattering coefficients is between those from rock or soil and wet snow. These differences in dielectric properties and surface roughness provide an opportunity to separate glacier, wet snow and bare rock or soil regions.

\section{POST-PROCESSING SAR DATA}

Because the back-scattering signals, especially for VV and $\mathrm{HH}$ polarizations, depend also on local incidence angle, the representation of the target materials is unlikely to be reliable for target discrimination purpose. This variation in radar back-scatter that is unrelated to the surface-cover type is particularly evident for high-relief surfaces. For example, in Figures 1 and 2 some rock surfaces have lower 
power return than from snow- or glacier-covered areas. The effect of incidence angle exists in alpine regions for both space-borne and air-borne SAR, and in flat regions for air-borne SAR.

If topographic information is available, we can use either an absolutely calibrated SAR image (in slant-range presentation) or a geocoded SAR image (in ground-range presentation) for target discrimination. The remaining question is: how can we reduce the effect of the local incidence angle?

As indicated by Ulaby and others (1982), two popular models for $\sigma^{0}\left(\theta_{\mathrm{i}}\right)$ are:

$$
\sigma^{0}\left(\theta_{\mathrm{i}}\right)=\sigma^{0}(0) \cos \left(\theta_{\mathrm{i}}\right)
$$

and

$$
\sigma^{0}\left(\theta_{\mathrm{i}}\right)=\sigma^{0}(0) \cos ^{2}\left(\theta_{\mathrm{i}}\right)
$$

The first model represents back-scattering from either densely packed spheres or a perfectly rough surface. In the second model, reradiation obeys a cosine law rather than being isotropic, typical of vegetation. In most situations, actual scattering variation seldom exactly matches either model. Generally, we consider the backscattering coefficient as a product of

$$
\sigma^{0}\left(\theta_{\mathrm{i}}\right)=\sigma_{\mathrm{n}}^{0} f\left(\theta_{\mathrm{i}}\right)
$$

where $\sigma_{\mathrm{n}}^{0}$ is a normalized back-scattering coefficient related to the target properties such as dielectric function, micro-structure of scatterers and surface roughness. The function $f\left(\theta_{\mathrm{i}}\right)$ represents the angular dependence of back-scattering coefficients for the given target, depending on the dominant scattering mechanism. Therefore, the angular dependence of back-scattering coefficients can be reduced if we normalize the measured back-scattering coefficients by $f\left(\theta_{\mathrm{i}}\right)$ when topographic information for the study area is available. The function $f\left(\theta_{\mathrm{i}}\right)$ can also be determined from sampling the local incidence-angle map and SAR image.

Figure $3 \mathrm{a}$ shows measurements from Figure 2 after normalization by $\cos ^{1.8}\left(\theta_{\mathrm{i}}\right)$. It indicates that the measurements for target discrimination can be significantly improved by normalizing back-scattering properties. Figure $3 \mathrm{~b}$ shows $\sigma_{\mathrm{n}}^{0}$ measurements normalized by $\cos ^{1.5}\left(\theta_{\mathrm{i}}\right)$ from $\mathrm{HH}$ polarization at $\mathrm{L}$ band, like the JERS-1 sensor. This frequency at single polarization cannot discriminate between wet snow and glacier ice, but it can distinguish snow or glacier from other surfaces.

SAR-image texture also provides useful information to improve classification results for snow and glacier mapping, because snow cover is generally uniform in spatial distribution, whereas more spatial variation in surface characteristics is always expected in rock regions. The texture measure for the SAR image used in this study is the normalized standard deviation, given by

$$
s_{\mathrm{T}}=s_{\mathrm{I}} / \mu_{\mathrm{I}}
$$

where $s_{\mathrm{T}}$ is the normalized standard deviation, $s_{\mathrm{I}}$ and $\mu_{\mathrm{I}}$ are local mean value and standard deviation of backscattering coefficients.
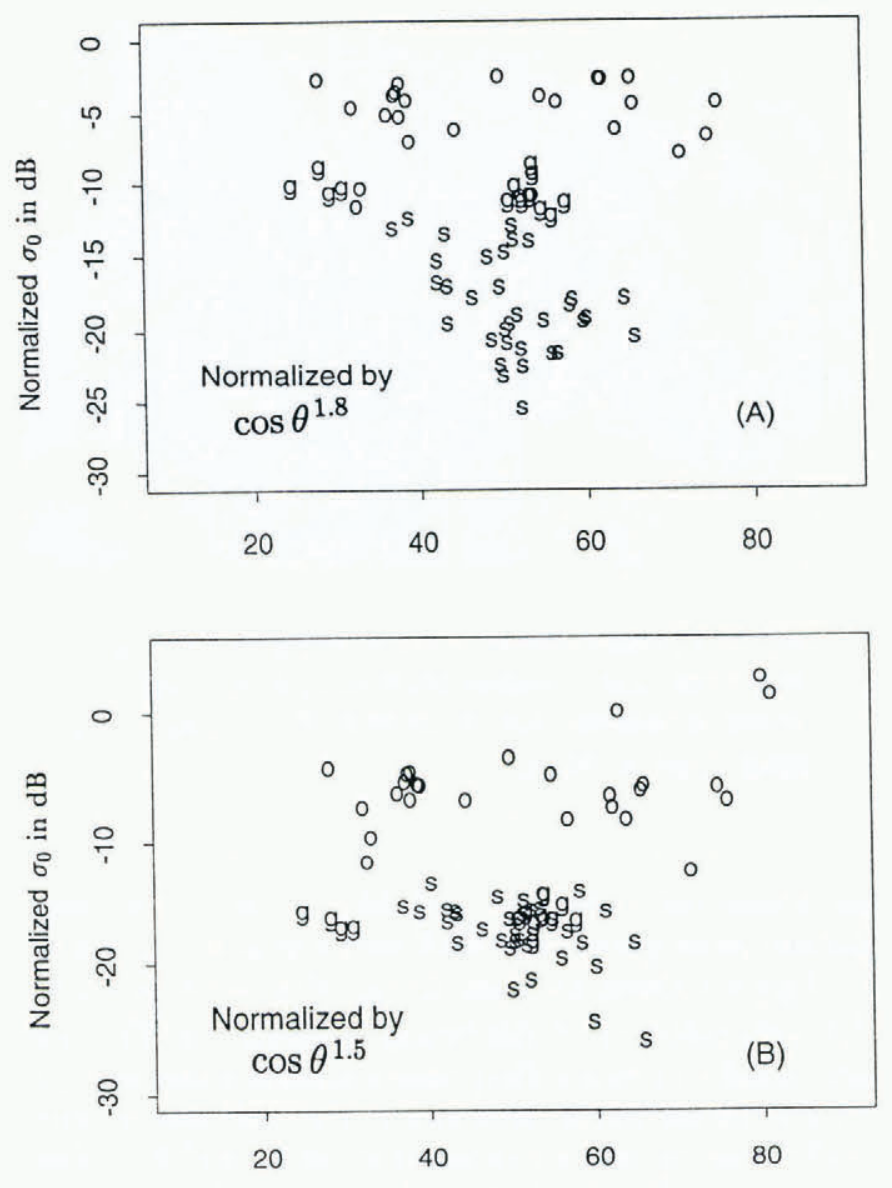

Incidence angle in degree

Fig. 3. Normalized back-scattering coefficients for three targets (as in Fig. 2). a. C band with VV polarization normalized by $\cos ^{1.8}\left(\theta_{\mathrm{i}}\right)$; and $b . L$ band with $H H$ polarization normalized by $\cos ^{1.5}\left(\theta_{\mathrm{i}}\right)$.

\section{COMPARISON OF CLASSIFICATION RESULTS}

To evaluate capabilities of the single-polarization SAR, we co-registered TM data to SAR data using control points and DEM data. The classification was performed on both TM and SAR data based on a supervised Bayes classifier. To reduce speckle and improve classification performance, a spatial function represented by the average of the back-scattering and texture variation over a $5 \times 5$ window was used. The classification results from SAR data were compared with those from TM data pixel-by-pixel, except the shadowed areas in SAR images were excluded. There are two factors that might affect this analysis: different sensor properties, including mixed pixels and penetration (TM measures the surface only but SAR measures sub-surface properties also); co-registration error (tested accuracy was about 2-3 pixels).

The classification based only on the normalized backscattering coefficients gave overall accuracies of $66 \%$ for both $\sigma_{\mathrm{n}}^{\mathrm{vv}}$ and $\sigma_{\mathrm{n}}^{\text {hh }}$ at $\mathrm{C}$ band. However, the classification accuracies increase about $8 \%$ when using both the normalized back-scattering coefficients and the texture measurements. The texture information especially improves the classification performance in rock regions. 


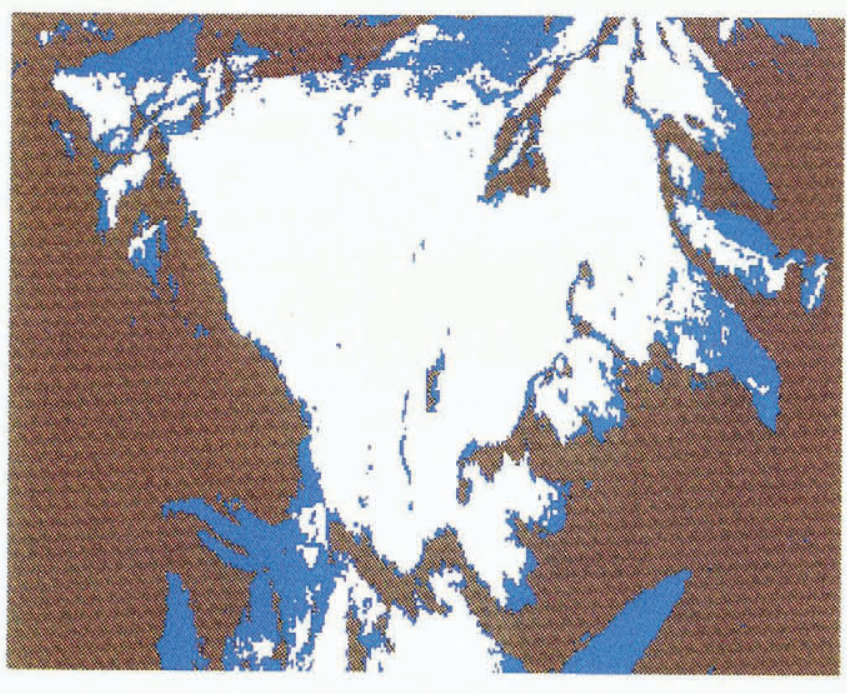

Fig. 4. Snow and glacier map produced by TM image. White is snow-covered area; blue is glacier ice; and brown is for all other targets, mainly rock and moraine.

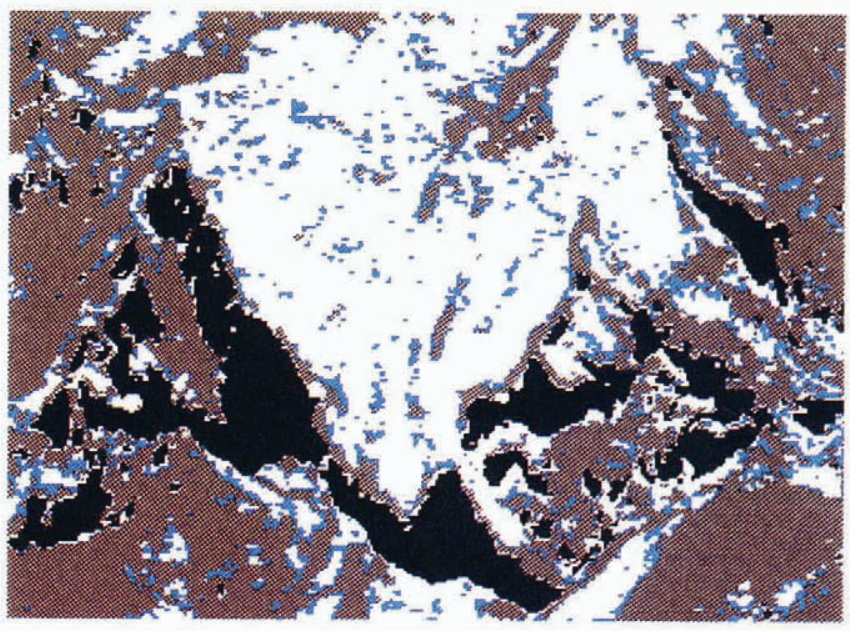

Fig. 5. Snow and glacier map produced by the SAR image using C-band VV polarization. Color presentations are the same as in Figure 4 for snow, glacier ice and other targets; radar-shadow areas are in black.

Table 1. Confusion matrix of classifications by TM and SARs in (\%)
Figures 4-6 show the classification results from TM imagery, C-band VV polarization and L-band $\mathrm{HH}$ polarization SAR data. Table 1 shows the confusion matrix of classifications by TM and SARs. The overall accuracies of classifications from SARs were determined by the sum of the products of the percentage in TM scene and accuracy of SARs for each target (Richards, 1986). Compared with TM data, the results at $\mathrm{C}$ band show a fairly good agreement for wet snow-covered area, 80 and $82 \%$ for $\mathrm{VV}$ and $\mathrm{HH}$ polarizations. But they poorly identify glacier ice, with only $40 \%$ accuracy, because of difficulty in discriminating glacier from bare rock or soil when the glacier has either a rough surface or is partially covered by rock debris. In the ice-free regions, the classified SAR-data accuracies reach 87 and $84 \%$. The mis-classifications mainly occur in the areas where the rock is smooth. The overall classification accuracies are 74 and $73 \%$ for $\mathrm{VV}$ and $\mathrm{HH}$ polarizations.

The results from L-band $\mathrm{HH}$ polarization SAR data show the best discrimination of ice-free regions with $90 \%$ accuracy, but at this frequency it is not usually possible to

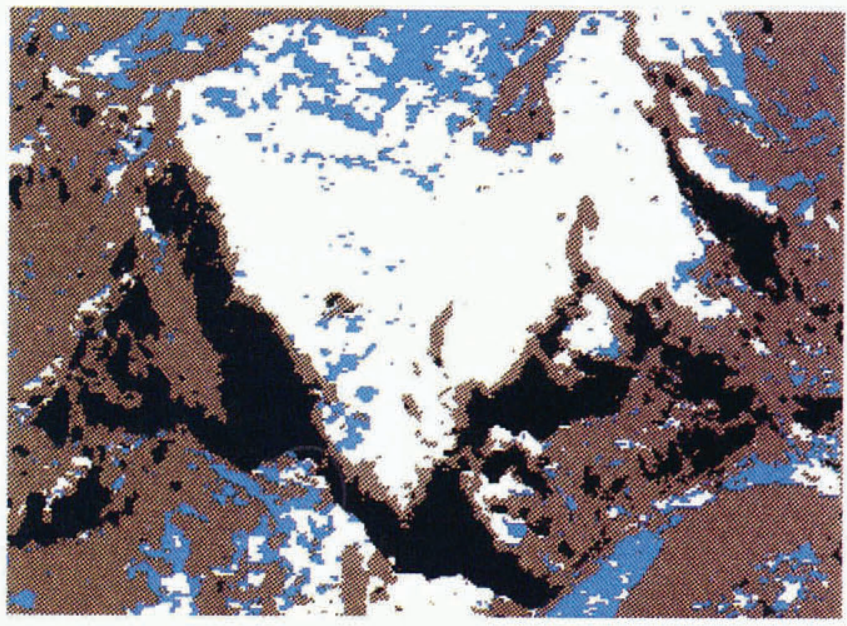

Fig. 6. Snow and glacier map produced by the SAR image using L-band HH polarization. Color presentations are the same as in Figure 5.

G

$\begin{array}{rrr}80.3 & 10.3 & 9.4 \\ 20.2 & 41.7 & 38.1 \\ 4.4 & 9.4 & 87.1\end{array}$

\section{5}

22.5

$\begin{array}{rr}6.0 & 12.5 \\ 40.8 & 36.7 \\ 10.4 & 83.7\end{array}$

36.8

10.6

46.8

37.9

16.4

$\begin{array}{ll}\mathrm{O} & 4.4\end{array}$

74.5

73.2

60.4

S Wet snow.

G Glacier ice.

O All other targets: mainly rock and moraine. 
separate wet snow from glacier ice. The overall classification accuracy is only $60 \%$.

\section{CONGLUSIONS}

Mapping snow and glaciers in remote alpine regions by a conventional single-polarization $\mathrm{SAR}$ requires topographic information in order to obtain the correct radiometric measurements and to reduce the angular dependence of the measurements. C-band VV and $\mathrm{HH}$ polarizations (like ERS-1 and Radarsat) have similar capabilities for snow and glacier mapping at the same viewing geometry. They provide good capability to map wet-snow and ice-free surfaces with accuracies greater than $80 \%$, but they poorly separate glacier ice from snow and rock. L-band $\mathrm{HH}$ polarization SAR (JERS-1) can distinguish snow or glacier from other surfaces but cannot discriminate between snow and glacier ice.

Overall, TM is better than SARs for mapping glacier ice in alpine regions, because the back-scattering measurements from SAR have much greater fluctuations than TM reflectances. These fluctuations are caused by greater sensitivity to the surface characteristics of the glacier ice, larger effect of topography and viewing geometry, and random signal fading (image speckle) caused by the coherent property of SAR sensors. Therefore, TM images may be used to monitor glacier boundaries when timely measurement is not needed. However, SARs can be used in all weather conditions. They can map a seasonally snow-covered area and monitor the change of the snow line on glaciers. Timely measurements of those parameters are required by hydrological investigations.

\section{ACKNOWLEDGEMENT}

This research is supported by the U.S. National Aeronautics and Space Administration under grant JPL/ NASA 958473.

\section{REFERENCES}

Richards, J.A. 1986. Remote sensing digital image analysis. Berlin, Springer-Verlag.

Shi, J. and J. Dozier. 1992. Radar backscattering response to wet snow. IGARSS'92. International Geoscience and Remote Sensing Symposium. International Space Year: space remote sensing ... Houston, Texas, May 26-29, 1992. Vol. 2, 927-929.

Shi, J., J. Dozier, H. Rott and R. E. Davis. 1990. Snow and glacier mapping in alpine regions with polarimetric SAR. IGARSS'91. Remote sensing: global monitoring for Earth management. 1991 International Geoscience and Remote Sensing Symposium, Helsinki University of Technology, Espoo, Finland, June 3-6, 1991. Vol. 4, 2311-2314.

Ulaby, F. T., R. K. Moore and A. K. Fung. 1982. Radar remote sensing and surface scattering and emission theory. In Ulaby, F. T., R. K. Moore and A. K. Fung. Microwave remote sensing: active and passive. Vol. 2. Reading, MA, Addison-Wesley Publishing Co., 4571064.

Zyl, J.J. van and J. Shi. In press. The effect of topography on SAR calibration. IEEE Trans. Geosci. Remote Sensing.

The accuracy of references in the text and in this list is the responsibility of the authors, to whom queries should be addressed. 